\title{
Ethical Sharing and Reuse of Qualitative Data
}

\author{
Libby Bishop
}

\begin{abstract}
The objective of this paper is to attempt to move beyond the impasse of ethical objections to reusing qualitative data. In doing so, there is no intention of dismissing the importance of ethical debates, in fact, quite the opposite. The debate about ethical reuse needs to be deepened and broadened. First, the current terrain of research ethics will be summarised and situated in the context of broader philosophical ethical frameworks. In contrast, the debates around ethics of archiving have often been narrowly focused on participants' rights. The framework of debate should be broadened first by recognising other entities traditionally deemed within the scope of research ethics, namely the scholarly community and the public. The second useful broadening of the framework is provided by a deontological ethical stance with its focus on duties. In the final section, this expanded framework will be used to rebut several common ethical arguments against archiving qualitative data: archiving violates confidentiality; informed consent for reusing data is impossible; reusing data violates trust between researcher and participant; and, archiving creates an unacceptably high risk of data misrepresentation. If a more general philosophical debate on ethics has something to contribute, the central message must be that no single ethical claim is incontestable. The conclusion will position these debates in a wider context by asking what is at stake when the boundaries of ethical discourse about sharing data are drawn too narrowly.
\end{abstract}

Keywords: archive, research ethics, qualitative data, reuse, 


\section{Introduction}

Until recently, discussions of qualitative data archiving reported that the practice of sharing qualitative data, while perhaps growing, still substantially lagged relative to the archiving and sharing of quantitative data. Though still largely true, in the past five years the situation has changed markedly, at least in the United Kingdom (UK) and some other parts of Europe (Corti et al. 2005; Mason 2007). In brief, there is a strong move toward data sharing, inclusive of qualitative data, with key benefits identified as: making "unmined" data available, avoiding duplication, reduced burden on research participants, greater transparency of research procedures, alignment with open access principles, and recognising that outputs of publicly funded research are public assets (Fry et al. 2008). Not every argument for data sharing is equally meritorious, as I will note in my conclusion, but there is a sense that norms are slowly changing.

Some of the change can be attributed to the policies of several international organisations that promote or recommend data sharing, that is, open access to publicly funded research, e.g., OECD, UNESCO, ESFRI (European Strategy Forum on Research Infrastructures), CODATA (Committee on Data for Science and Technology) and others (Ruusalepp 2008). Within the UK, numerous organisations have policies supportive of data sharing, such as the Research Councils UK (DCC 2010), Joint Information Systems Committee (JISC 2009), and the Research Information Network (RIN 2008). More specific policies about data sharing exist at the level of individual funding agencies.

Most qualitative social science research in the UK is funded by the Economic and Social Research Council (ESRC). The ESRC Data Policy (ESRC 2000) requires all award holders to offer for archiving and sharing copies of both digital and non-digital data to the Economic and Social Data Service. There are only a few additional mandates requiring sharing, but recently there has been an increase in funders in the UK and other countries requiring data management plans which obligate researchers to take into account data sharing and curation in the design and implementation of their projects (Cheshire 2009; Ruusalepp 2008: Table 3).

Still, arguments against archiving qualitative data persist, and even if the trend may be toward sharing, there is still significant opposition. The most common arguments against archiving are typically technical, methodological and ethical (Broom 2009; Gray and O'Connell forthcoming; Kuula forthcoming). Technologies of sharing, while by no means resolved, are steadily being improved (Corti 2005). The methodological debate continues, primarily over context (see Bishop 2006 and related articles in the same special issue), but Moore's (2007) reframing of the debate from 'secondary analysis' to 'recontextualisation' is becoming more widely accepted. Ethical challenges, however, remain highly contentious. Critics of archiving cite duty of confidentiality to participants, anonymisation (e.g., feasibility, damage to data, etc.), informed consent, and more. At the UK Data Archive (UKDA), researchers can request waivers to be exempt from depositing data, and ethics-related reasons (i.e., lack of consent, confidentiality, etc.) are the most frequent reasons 
given, affecting up to $25 \%$ of qualitative collections offered (Deswarte 2009; Van den Eynden 2008). More problematically, often such ethical claims are presented as incontestable by virtue of being grounded in ethical protection of participants. In this paper I hope to address some of these ethical challenges to qualitative data sharing.

The objective of this paper is to attempt to move beyond the impasse of ethical objections to reusing qualitative data. In doing so, there is no intention of dismissing the importance of ethical debates, in fact, quite the opposite. The debate about ethical reuse needs to be deepened and broadened. First, the current terrain of research ethics will be summarised and situated in the context of broader philosophical ethical frameworks. In contrast, the debates around ethics of archiving have often been narrowly focused on participants' rights. The framework of debate should be broadened first by recognising other entities traditionally deemed within the scope of research ethics, namely the scholarly community and the public. The second useful broadening of the framework is provided by a deontological ethical stance with its focus on duties. In the final section, this expanded framework will be used to rebut several common ethical arguments against archiving qualitative data: archiving violates confidentiality; informed consent for reusing data is impossible; reusing data violates trust between researcher and participant; and, archiving creates an unacceptably high risk of data misrepresentation. If a more general philosophical debate on ethics has something to contribute, the central message must be that no single ethical claim is incontestable. The conclusion will position these debates in a wider context by asking what is at stake when the boundaries of ethical discourse about sharing data are drawn too narrowly.

\section{Philosophical and research ethics}

Space does not permit a detailed examination of philosophical applied ethics. Nor is such an examination necessary as the goals of philosophical and research ethics are distinct, the former pursuing theoretical clarity and consistency, while research ethics needs to offer guidance for research practice. In fact, research ethics often draws upon multiple, and even conflicting, philosophical frameworks (Ess and the AoIR Ethics Working Committee 2002; Hammersley 2009; Reynolds 1979). Nonetheless, some familiarity with basic philosophical foundations can better inform discussions of practical research ethics.

Research ethics requires a method of assessing behaviour and actions. There are three broad moral theories that offer a way to judge the morality of actions. Consequentialism assesses an act according to its outcome or the results of that action. Deontological approaches argue that the morality of acts must be judged by examining factors apart from outcomes such as intentions, duties and rights. Agent-centred theories typically focus on duties whereas patient-, or victim-centred theories are rights-based (Stanford Encyclopaedia of Philosophy 2009). The third theory of virtue ethics is based on human flourishing and the human virtues necessary to realise it (LaFollette 2000). (There are additional views that I take up in other work, but can not be adequately addressed here.) 
Opinions vary widely about the scope of moral judgement. For researchers, one central dilemma is how to proceed when the development of knowledge and possible social benefits infringe on the rights of individuals (Reynolds 1979). All three moral theories address this dilemma. Consequentialism (in particular, utilitarianism) allows that acts that increase the overall good are moral and such acts can be morally right even if some are harmed. Deontological theories stress a central role of agency. Rights-based versions speak directly to many research dilemmas by specifying that a person has, as a core right, the 'right against being used only as means for producing good consequences without one's consent' (Stanford Encyclopaedia of Philosophy 2009). Much international and national legislation has been based on deontologically-based rights formulations: The Universal Declaration of Human Rights 1948, the European Union Data Privacy Act 1995, and in 1998, the UK Data Protection Act. Finally, virtue ethics points to the importance of developing researchers' character through good ethical training to ensure that they make moral decisions.

It is possible to be more specific and see how these frameworks shape formal statements of research ethics guidelines. There are, of course, numerous such guidelines, highly varied by discipline, nationality, etc. To make the point, I will look at just four, the British Sociology Association Statement of Ethical Practice (BSA 2009), the United Kingdom's ESRC Research Ethics Framework (ESRC 2009), the Australian National Statement on Ethical Conduct in Human Research (NHMRC 2007) and the guidelines from the RESPECT Project, a European Commission Programme to write ethical guidelines for socio-economic research (RESPECT 2009). Although they vary in degree of detail and in some specifics, all four sets of guidelines share several elements. These can be summarised by looking at the duties or responsibilities researchers have toward various actors in the research process. To participants, researchers owe a duty to avoid or minimise harm, provide informed consent, and protect confidentiality. To the scholarly community, there is the responsibility to maintain professional standards of conduct with transparency and integrity. Finally, to the public at large, including funders, there is a duty to produce quality research of wider social value. All four are far more nuanced; I have highlighted these elements to make the following points.

Research ethics - as codified in these and other codes of practice and guidelines - reflect the complexity of actual research practice. In different ways, these statements draw on diverse philosophical frameworks and attempt to grapple with challenging, even contradictory, duties and rights, involving a diverse set of actors. In fact, many general statements of research ethics highlight these same points, stressing the need to assess numerous factors that may potentially conflict (Levitt and Williams 2005). In contrast, too often the critics of reusing qualitative data have narrowly construed the debate to focus solely on participants - to exclusion of other agents-and rights - to exclusions of duties. Such arguments do not do justice to the depth of moral debate required. 


\section{Duties and Rights}

A focus on duties, informed by a deontological ethical stance, is a useful extension to the current debates. Within philosophical ethics, there are several defences of duty- over rights-based claims. One position is taken by Onora O'Neill in her Reith Lectures (2002: 29) in which she argues that rights-based approaches are incomplete.

Declarations of rights ostensibly offer something to everybody, without coming clean about the costs and demands of respecting the rights they proclaim...Duties are the business end of justice: they formulate the requirements towards which declarations of rights gesture....

It is worth noting that challenges to the dominant use of rights exists even in medical research where risks of harm to participants are nearly always higher than in social research and the benefits of research often more direct. The Declaration of Helsinki is often cited to defend subjects' rights, even when the research may benefit the wider society. However, bioethicist John Harris (2005: 244) counters that:

The rights of the subject cannot be paramount nor can they automatically take precedence over other interests of comparable moral significance...the rights and interests of research subjects are just the rights and interests of persons and must be balanced against rights and interests of other persons.

Paul Spicker (2007: 3) makes the comparable point for social research: 'The rights of research participants are not unlimited and they do not pre-empt other ethical issues'.

Which duties and to whom are relevant in the debate about reusing data? First, regarding participants, most codes prescribe that participants should be exempt from unnecessary intrusion. Arguably, if data already exist to address a research question, further collection of primary data could be seen as intrusive. While reuse opponents focus on participants' right to exclude their data from an archive, far less is said about researchers' duty to abstain from duplicative data collection. Second, regarding the scholarly community, there is a clear duty of openness and transparency, and this is increasingly being seen to include data, along with methodology and findings. Finally, regarding the public interest and wider society, there is a duty to benefit society, directly or by increasing knowledge and understanding. These gains, especially if significant, must be weighed against minimal harms with low risk to participants. This is, of course, the moral justification for many medical clinical trials. In the social sciences, research outcomes rarely mean life or death; however, researchers do make strong claims about benefits of their work to social policy and to expanding knowledge. If these claims are authentic, and not merely justifications for funding proposals, then these benefits have to be weighed against the risks of harm, often minimal, of archiving data. 


\section{The ethics of (not) asking for consent to reuse}

In this and the following sections, I explore several interconnected issues of ethics and reusing data. To begin, I ask if there is a moral responsibility to seek consent for archiving. Then I proceed to the legitimacy of arguments against archiving such as duty of confidentiality, forms of consent, relationships with participants, and misrepresentation of data .

Let us first consider the case where consent for archiving has not been obtained because researchers did not ask for it. There may be many reasons for not having gained consent (some of which I will consider later), but the case can be made that researchers have a responsibility to at least attempt to gain consent for archiving. As has been argued by others, there are a growing number of professional guidelines that call for data sharing and the point is made explicit in the Research Ethics Framework (ESRC 2009: 19):

Researchers who collect the data initially should be aware that ESRC expects that others will also use it, so consent should be obtained on this basis and the original researcher must take into account of the long-term use and preservation of data.

So, there appears to be a formal duty to seek consent so as to permit reuse, subject to additional criteria such as 'reasonable' uses and 'sufficient' explanations. The codified guidelines are less important than the rationales they offer: transparency and openness in scholarly debate and making fullest possible use of publicly funded research data. These points make clear that, while in no way undervaluing the duty to protect participants' confidentiality, equal consideration must be given to duties to the scholarly community's standards and to society at large.

In some cases when researchers have not discussed archiving with their participants, they will defend their actions based on their belief that participants will refuse, so there is no point in even raising the issue. In these situations, researchers believe they know their participants' wishes and, pre-emptively, do not seek consent for archiving. There is little research in this area, but one outstanding research project in Finland found striking evidence. The Finnish Data Archive sought to gain consent to preserve several collections of qualitative research. The original researchers had not asked for consent, but the archivist had gained permission from the researchers to contact participants directly to gain re-consent for archiving. In total, 169 participants were successfully contacted: 14 did not respond, 4 refused and 151 (89\%) agreed to have their data archived, casting rather strong doubts on the accuracy of the original researchers' understanding of their participants' wishes (Kuula forthcoming). Equally important, this evidence suggests that the duty to provide participants with appropriate visibility of their data must be weighed along with the protection of their rights. 


\section{Can confidential data be archived and shared?}

While researchers may have many reasons for not seeking consent for archiving, there is little doubt that many are confused, and justifiably so, about potential conflicts between requirements to share data and responsibilities to participants (Thomas and Walport 2008; Van den Eynden and Corti 2009). Frequently cited is the belief that a researcher's duty to protect confidentiality precludes asking for archiving and reuse of data. Some researchers may use promises to treat data with care (even beyond what is ethically or legally necessary) as a way of building rapport with participants to gain their consent to participate. This may result in the writing of consent forms that prevent data reuse by, for example, promising that data will be used only by the primary research team or that data will be destroyed at the end of the project. The UKDA continues to receive numerous datasets with these problems; we have obtained permission to share selected consent forms, some of which impose such conditions (UKDA 2008). Researchers may also be asked to include such provisions by ethics review committees that are inadequately informed in the area (Cheshire 2009). In such situations, it is hardly surprising that researchers may be confused about duty of confidentiality and, quite sensibly, prefer to minimise their risks.

Researchers clearly have a duty to handle data responsibly. However, there is a common misunderstanding that all research data is confidential when this is not necessarily the case. If confidentiality has been promised or implied, then the duty of confidentiality applies. Otherwise, only personal or sensitive (defined by the Data Protection Act) data would be considered confidential (UKDA 2009a). These distinctions are important legally, but most researchers are, rightly, not guided by legal requirements alone as these may be seen as too lax. In many cases, implied or explicit confidentiality will apply, but even in such circumstances, there are options for archiving and reusing data.

The UK Data Protection Act is clear that personal and confidential materials can be shared with the participant's consent (Thomas and Walport 2008). In fact, all manner of data may be archived (e.g., text, images, audio and video recordings, qualitative data software files, researchers' notes, etc.) with appropriate precautions explained below. Yet there is still reluctance to seek such consent for archiving, and often this reluctance can be attributed to lack of understanding of how confidentiality can be maintained after materials have been deposited into an archive. Researchers may believe only raw (unanonymised) data can be archived, that they have no control over which materials can be archived, or that archived data will be publicly accessible. None of these assumptions is true.

The UKDA and other qualitative data archives (Timescapes, the Irish Qualitative Data Archive, and the Finnish Data Archive (FSD)) all maintain comprehensive systems for protecting data. Typically, these systems have at least three elements. First, they recommend obtaining consent at the time of data collection for the key purposes to which the data may be put: research and publication as well as archiving and reuse. The UKDA and FSD provide guidelines for informing participants and the UKDA provides templates of consent forms, both generic versions and those specific to special conditions, such as working with children 
(FSD 2004; UKDA 2008). The second element is the removal of personal or sensitive information by employing pseudonyms or other anonymisation procedures. The UKDA advocates that anonymisation be done by researchers prior to depositing data. Anonymisation can be difficult and requires detailed knowledge of the data (Clark 2006; Thomson et al. 2005). The UKDA and FSD provide general guidelines and in many cases, projects intending to deposit data share their anonymisation procedures (FSD 2004; Timescapes 2009; UKDA 2009b).

The third element protecting confidentiality is a rights management framework under which materials are deposited, preserved and disseminated to users. At the UKDA, the 'Licence Agreement' specifies the rights and responsibilities of the depositor and the UKDA. The 'End User Licence' requires users of the data collection to respect confidentiality and not to disseminate any identifying information and has contractual force in law (ESDS 2009). In addition to these standard protections, depositors can impose bespoke conditions on uses of, and access to, data. For especially sensitive research data, additional restrictions may be imposed beyond the standard license. Data access authorisation may be required from the data depositor prior to release of the data or sensitive data may be placed under an embargo for a given period of time. This is decided on a case-by-case basis in dialogue between the UKDA and the data depositor.

This degree of access control is essential for 'hard to anonymise' and other sensitive data. Data vary in how amenable they are to these procedures. Visual data, for example, can be technically altered (e.g., digitally blurred faces), but at high cost to the integrity and quality of the data. Similarly, qualitative longitudinal data is challenging to anonymise, even textual transcripts, as the accumulation of personal, geographic, and other details over time becomes more disclosive than most cross-sectional interviews. The Timescapes Qualitative Longitudinal Study is using a system of four levels of access that will permit each file in the collection to be assigned a unique access group: public, registered users who sign a standard licence, users approved on a case-by-case basis, or embargoed (Timescapes 2009).

\section{Can consent for reuse be 'informed'?}

A second debate about reuse focuses on what standards must be met if consent is to qualify as 'informed'. In some cases, reference is made to provisions in the Declaration of Helsinki that requires consent to be 'explicit' and 'specific' (Manson and O’Neill 2007). Under narrow interpretations, this requires all consent to be explicit, i.e., in writing, and that the information include details about research procedures and even possible outcomes.

Clearly, neither researchers nor archivists can say in detail all possible ways data might be reused after it has been archived. Thus it seems logically impossible to meet the requirements of explicit consent for data sharing. But this is not the end of the debate, as the Helsinki Declaration, and other guidelines that call for 'full' consent have been challenged regarding primary research as well as reuse. One critic is Reynolds (1979: 95): 
No individual can be fully informed regarding the procedures and possible effects associated with a research project; if there were full information, there would be no reason to conduct the research.

What the debate makes clear is that all consent is partial. No one can actually provide full information about how research will be done, or no research could get done. Any criticism of less-than-full consent does not apply only to archived data for reuse. For example, in much emergent and exploratory research, details of procedures and even core research questions may not be known at the time participants are asked to give their consent. So in fact, for much primary research, consent can not be specific, explicit or full.

Fortunately, the inability of researchers to obtain explicit consent need not be a barrier to data sharing. As is done for primary research, it is possible to provide more general information about the nature of the research, the most likely procedures, or, in the case of archiving, examples of ways similar materials have been used, typical reusers, and so on. This is the emerging strategy in medical research and in social research as well, and is called unspecified or blanket consent, or open-ended permission (Greely 1999). In a similar vein, there is growing acceptance of process rather than one-off consent, enabling participants to have ongoing reflection on their consent status (Cutliffe and Ramcharan 2002). In sum: archiving data does not present insurmountable challenges for consent and confidentiality, providing additional precautions are taken. In most instances, the challenges are in fact the same as, or closely related to, problems for primary research.

Recognizing that fully informed consent may be impossible always to achieve puts researchers in a powerful and highly responsible position, and means that they have a greater, not a lesser, duty to engaged in a reflexive and sensitive moral research practice (Mason 2002: 82).

\section{Does archiving harm the researcher-participant relationship?}

A third challenge to archiving and reusing data is directed to the nature of the relationship between the researcher and the participant. The core of the argument is that, as distinct from empiricist perspectives, qualitative research founded in constructionism succeeds largely through relating to and interacting with participants. The relationship may even become a close, personal one. In this view both the nature and the quality of the data produced depend on this relationship (Broom, et al. 2009; Carusi and Jirotka 2009; Perry and Mauthner 2004).

This paper will not attempt to resolve the long-standing epistemological debates among positivists, interpretivists, realists (social or naïve), and others. While much qualitative research, especially feminist research, may depend on these relationships, a great deal of research does not, and in fact, it is just as plausible for there to be some degree of tension or even antagonism present such as in evaluation research, critical research, and research on groups with anti-social 
norms. Blee's (2006) research on the Ku Klux Klan is a prime example of the researcher not empathising with research participants. Covert research does not depend on closeness, unless one believes that a close personal relationship can be founded on deception. For other data, relations are simply of lower intensity, though these relationships can still have features of mutual respect, sympathy, and gratitude. Even when researchers perceive their relationships with participants as close, participants often perceive these as institutional interactions which they are quite capable of managing (Kuula forthcoming). When the data are not derived from a close relationship, closeness can not be an obstacle to reuse.

Where the relationship is a close one, it is essential to be more specific about what, precisely, does not happen between researchers and participants when reusing data that does (or at least may) happen in primary research. The first point addresses the presence of the researcher at the point the data were collected. Typically what is described is the importance of the researcher in taking in the full context of the situation, including body language, setting, voice tone, etc. that cannot be captured in full, regardless of the comprehensiveness of description or fidelity of recording technologies. This debate cannot be repeated here, and is elaborated in Moore (2007), and in a special issue of Methodological Innovations Online (Corti 2006), but two comments need noting. First, all data analysis must address partial context; only the degree of incompleteness varies. Second, there is an unresolved issue as to how data that are co-constructed can also be shared-within teams, in publications, and in archives.

The second point, which will be taken up more fully here, concerns the role of participants in the data collection and analysis process. A key difference between original research and reuse is apparent: participants can not have a direct role in the research process in reuse projects. (While it is possible for participants to be recontacted for reuse studies, this is laborious and becomes impossible over time.) It is incontestable that such a direct role for participants is not possible in reuse; it is however very much contested whether such a role is necessary or even desirable for all qualitative research. The question then becomes: is reuse impossible, or in some way wanting, possibly even unethical, by making such relations impossible? The answer is no, and again, as with consent, what becomes clear is that the issue-the active role of participants in analysis and interpretation-is a lively and worthy debate, but the fault lines are not primary/ reuse; the debate occurs about primary research itself.

The case of Borland's (2006) research on her grandmother using a life story narrative may be illustrative. The grandmother tells Borland about an incident which she interprets as her grandmother resisting male authority. In her analysis, Borland labels the act 'feminist', but her grandmother does not agree. There is a long period of negotiation during which Borland and her grandmother both move their positions and reach a partial, but not full, agreement. While it may be laudable that such negotiation was done, it was not mandatory. If the data had been archived, the negotiation could not have happened in that 
way, but may happen in different forms. (In a similar way, laudable examples exist of secondary researchers taking issue with some interpretations of their predecessors in a sensitive and reflexive manner (Bornat 2003; Savage 2005; Thane and Evans forthcoming). Another researcher should be allowed to use the grandmother's data as evidence for a feminist interpretation, even if the grandmother would (perhaps) have disagreed with that interpretation. (Psychosocial researchers claim their approach can yield a deeper meaning than that of simply giving 'voice' to participants (Hollway and Jefferson 2000)). The standing of the new interpretation would have to depend on the data chosen and the analysis being openly debated; many researchers would concur that the final conclusions are not obliged to mirror the grandmother's own interpretation.

In their critique of archiving, Parry and Mauthner (2004) oppose the practice of secondary analysis on the grounds that some conclusions may be at odds with participants' desires. More recently, Carusi and Jirotka (2009) make a similar point, arguing against any secondary research for 'purposes which go against research participants' personal values and beliefs'. However, as the Borland example shows, this debate is not about reusing data; reusing data simply brings into sharper relief an epistemological debate that is less often highlighted in primary research. The issue is about participants' roles in research, and especially how much say they have in data interpretations and research conclusions, not about whether reuse violates rights of participants.

In this debate, other researchers take equally firm opposing positions, denying that any one standpoint, whether participant or researcher, should predominate:

Just as I have argued that a single researcher cannot unequivocally claim epistemological privilege simply because they belong to a specifically defined social group or occupy a specific social location, so too we cannot assume that a single research subject (or even a group of research subjects) unequivocally possesses such privilege (Mason 2002: 193).

Some would go further and argue that researchers should not even be obliged to gain consent from participants for how data will be interpreted.

Many researchers would argue that it is not necessarily desirable to gain consent from study participants for how their data are used in that this would curtail researchers' freedom to interpret their data and curtail the critical nature of the discipline (Wiles et al. 2006: 294).

To conclude, there is a legitimate debate about participants' roles in analysis, but unless critics are willing to argue that participants must have a role in research, to satisfy epistemological or ethical criteria, then the argument can not be an effective critique of archiving and reuse. 


\section{Does reusing data risk its misrepresentation?}

The final argument I will explore is researchers' concerns that archived data will be misused (Alderson 1998; Broom et al. 2009). One key fear is that archived data may be used to reach different, even opposing, conclusions from what the primary researcher intended. But these concerns are not foreign to natural scientists, artists, and others. For historians, for example, the idea of multiple, and even unimaginable, uses for data comes more easily.

However intelligent and well thought out his work, it is inconceivable that his will be the only selection of texts that could be made. The information which he brushes aside as irrelevant may be just the thing upon which a future researcher will seize-if he is given the chance. Research can never be a once-and-for-all affair, nor is there ever a single use to which evidence can be put (Samuel 1998: 392).

Several commentators have astutely noted the irony when those subscribing to an interpretivist paradigm claim that the primary researcher in the social sciences has 'epistemic transcendence' or an 'unassailable insight' into the data (Cheshire 2009; Kuula forthcoming).

Some will then respond by claiming that the project of social science is different from art, or natural sciences, or even history, typically citing the interpretivist epistemological assumption that data are not objectively out there, but (inter-) subjectively constructed. If so, then the question remains of how to adjudicate between competing interpretations of co-constructed data. And this issue, as with context and consent, is not a matter of archiving but of epistemology and the nature of academic debate.

In the focus groups facilitated by Broom et al. some researchers described their relationships with data as "'intuitive', 'organic', 'intimate', and 'personal'.

Ultimately, it was an encoded account only decipherable to the individual who collected it." (Broom et al. 2009:1170). The logical extension of such a stance does, I suggest, leave researchers on flimsy footing. It is no different from saying 'trust me, I was there'. This will not do; if a second researcher made an opposing argument, it is unlikely that the first researcher would accept it with such uncritical trust.

What is at issue here is not reuse at all, but scholarly procedures, including sharing data, for assessing validity. Some qualitative researchers find the term validity problematic, but I am not using the term in its narrow, positivistic sense. What I mean, put simply, is why should anyone believe my claims and not those of my counterpart? Researchers have to defend their analyses, interpretations and conclusions, and the presence of archived data may be relevant, but the issue-adjudicating competing claims-exists whether or not data are archived. Further ways to show validity can place equal emphasis on exposing procedures, the paths that led to an interpretation (Mason 2002). Sharing data is part of this process; it is not the only way, and not suitable in all cases, but it should be the default, barring special circumstances. Indeed even with sensitive data, 
researchers should be willing to invest in (and funders should support) creative ways to make data sharable, such as anonymisation, composites or schemes of limiting access such as archiving partial collections, showing the data only to approved researchers or imposing embargoes.

In sum, a claim to validity of findings can not be asserted without the reciprocal duties to share research data and methodology. The duties operate at two levels. The first duty is to the scholarly community, to abide by norms and practices for debate and argumentation. The second duty is to the public. As both participants in research and its funders, when asked why a research claim should be believed, they deserve a better answer than, 'trust me, I was there.' If nothing else, this final issue shows that debates on ethics and epistemology are closely intertwined. Although this paper has focused on the ethical debate, the epistemological debate about data sharing warrants further treatment.

\section{Conclusion}

This paper contends that objections to archiving and sharing data that are based on ethical arguments that focus predominantly on participants' rights, especially confidentiality and consent, are incomplete. Disproportionate attention to participants excludes other legitimate agents, and too much emphasis on rights neglects corresponding duties. A perspective informed by considering philosophical and research ethics more broadly suggests that duties are owed to entities other than participants. To other scholars, there are duties of transparency and upholding professional standards, and to the public, there duties of openness and effective use of public funds. And even to participants, there are duties that must be considered in addition to protecting privacy, such as the need to avoid unnecessarily duplicative data collection and to assure that participants' data is fully utilised for the public good. In the aforementioned Finnish project, participants cited a 'wish to advance science' as the main reason they wanted their data archived (Kuula forthcoming).

There is much to be gained by broadening the debate on ethical data sharing. In many cases, the arguments against archiving highlight related arguments in primary research. This does not invalidate those arguments but it suggests the points of contention do not simply concern data sharing, thus analyses of the underlying ethical and, in particular, the epistemological arguments, are required. Second, many ethical critiques of archiving presume that all qualitative research is of a particular genre, whether interpretivist, constructionist, feminist, or others. Archiving practice must accommodate many genres and so can not be determined by any one of them. Researchers and archivists need to engage in these debates, while taking care not to allow internecine battles to become too distracting. The practices and infrastructures of scholarship-research and archiving - are increasingly subjected to the ideology of managerialism and commercial criteria. Researchers and archivists have much to gain by joining forces to defend independent scholarship. 


\section{Acknowledgements}

I am grateful to colleagues at the UK Data Archive and Timescapes for their conversations and comments on this paper. I also want to thank Natasha Mauthner for our on-going dialogue about ethics, epistemology, and archiving. All errors remain my own.

\section{References}

Alderson, P. (1998) 'Confidentiality and consent in qualitative research', BSA Network, (69), 6-7.

Bishop, L. (2005) 'Protecting respondents and enabling data sharing: Reply to Parry and Mauthner', Sociology, 39(2), 333-336.

Bishop, L. (2006) 'A proposal for archiving context for secondary analysis', Methodological Innovations Online, 1(2). Available online: http://erdt. plymouth.ac.uk/mionline/public_html/viewarticle.php?id=26\&layout=html.

Blee, K. (2006) 'Evidence, empathy and ethics'. In R. Perks and A. Thomson (eds.), The Oral History Reader (2nd ed.), London, Routledge.

Borland, K. 2006 “That's not what I said': Interpretive conflict in oral narrative research'. In R. Perks and A. Thomson (eds.), TTThe Oral History Reader (2nd ed.), London, Routledge.

Bornat, J. (2003) 'A second take: Revisiting interviews with a different purpose', Oral History, 31(1), 47-53.

Broom, A., Cheshire, L. \& Emmison, M. (2009) 'Qualitative researchers understandings of their practice ad the implications for data archiving and sharing', Sociology, 43(6), 1163-1180.

BSA (2002) 'Statement of Ethical Practice', British Sociological Association, http://www.britsoc.co.uk/equality/Statement+Ethical+Practice.htm, Date Accessed: 16 January 2010.

BSA (2006) 'Statement of Ethical Practice for the BSA - Visual Sociology Group', British Sociological Association, www.visualsociology.org.uk/about/ ethical_statement.php, Date Accessed: 16 January 2010.

Carusi, A. \& Jirotka, M. (2009) 'From data archive to ethical labyrinth', Qualitative Research, (9), 285-298.

Cheshire, L. (2009) 'Archiving qualitative data: Prospects and challenges of data preservation and sharing among Australian qualitative researchers', Discussion paper of The Australian Qualitative Archive, University of Queensland, Brisbane, Australia.

Clark, A. (2006) 'Anonymising research data', NCRM Working Paper Series, ESRC National Centre for Research Methods, Southampton, Available online: www.ncrm.ac.uk/research/outputs/ publications/ WorkingPapers/2006/0706_anonymising_research_data.pdf.

Corti, L. (2005) 'Qualitative archiving and data sharing: Extending the reach and impact of qualitative data', IASSIST Quarterly, 29(3). Available online: http://iassistdata.org/publications/iq/iq29/iqvol293 corti.pdf. 
Corti, L. (ed.) (2006) 'Making qualitative data more re-usable: issues of context and representation' Special issue of Methodological Innovations Online, 1(2), Available online: http://erdt.plymouth.ac.uk/mionline/public_html/ viewissue.php?id=2.

Corti, L., Witzel, A. \& Bishop, L. (eds.) (2005) 'Secondary analysis of qualitative data', Forum Qualitative Sozialforschung/Forum: Qualitative Social Research, 6(1). Available online: http://www.qualitative-research.net/ fqs/fqs-e/inhalt1-05-e.htm.

Crow, G., Wiles, R., Heath, S. \& Charles, V. (2006) 'Research ethics and data quality: The implications for informed consent', International Journal of Social Research Methodology (9), 83-95.

Cutliffe, J. \& Ramcharan, P. (2002) 'Levelling the playing field? Exploring the merits of the ethics-as-process approach for judging qualitative research proposals', Qualitative Health Research, 12(7), 1000-1010.

OPSI (1998) 'Data Protection Act 1998', Office of Public Sector Information, http://www.opsi.gov.uk/Acts/Acts1998/ukpga_19980029_en_1, Date Accessed: 16 January 2010.

Deswarte, R. (2009) ESDS Social History Data Manager, personal email communication.

DCC (2009) 'Digital Curation Centre: Curation Policies', Digital Curation Centre, http://www.dcc.ac.uk/resource/curation-policies/, Date Accessed: 13 January 2010.

ESDS (2009) 'Creating and Depositing Data', Economic and Social Data Service, http://www.esds.ac.uk/aandp/create/createintro.asp, Date Accessed: 16 January 2010.

ESRC (2009) 'Research Ethics Framework', Economic and Social Research Council, http://www.esrc.ac.uk/ESRCInfoCentre/Images/ESRC_Re_Ethics_ Frame_tcm6-11291.pdf, Date Accessed: 16 January 2010.

ESRC (2000) 'Data Policy', Economic and Social Research Council, http:// www.esrcsocietytoday.ac.uk/ESRCInfoCentre/Images/DataPolicy2000_ tcm6-12051.pdf, Date Accessed: 16 January 2010.

Ess, C. and the AoIR Ethics Working Committee (2002) 'Ethical decision-making and Internet research: Recommendations from the AoIR ethics working committee', Association of Internet Researchers, www.aoir. org/reports/ethics.pdf, Date Accessed: 16 January 2010.

Fry, J., Lockyer, S., Oppenheim, C., Houghton, J. and Rasmussen, B. (2009) 'Identifying Benefits arising from the Curation and Open Sharing of Research Data', UK Higher Education and Research Institutes', November. Access online: http://ie-repository.jisc.ac.uk/279/

FSD (2004) 'Other Services', Finnish Social Science Data Archive, http://www. fsd.uta.fi/english/other_services.html, Date Accessed: 16 January 2010. 
Greely, H. T. (1999) 'Breaking the stalemate: A prospective regulatory framework for unforeseen research uses of human tissue samples and health information', Wake Forest Law Review, (34), 737-766.

Hammersley, M. 2009 'Against the ethicists: On the evils of ethical regulation', International J of Social Research Methodology (12), 211-225.

Harris, J. (2009) 'Scientific research is a moral duty', Journal of Medical Ethics, (31), 242-248.

Heery, R. \& Powell, A. (2006) 'Digital Repositories Roadmap: Looking Forward', UKOLN and Eduserv Foundation, http://www.jisc.ac.uk/ whatwedo/programmes/reppres/keydocs.aspx, Date Accessed: 16 January 2010.

Hollway, W. \& Jefferson, T. (2000) Doing Qualitative Research Differently, London: Sage.

JISC (2009) 'JISC Strategy 2010-2012' Joint Information Systems Committee, http://www.jisc.ac.uk/media/documents/aboutus/strategy/strategy1012.pdf, Date Accessed: 16 January 2010.

Kuula, A. (forthcoming) 'Methodological and ethical dilemmas of archiving qualitative data', IASSIST Quarterly.

LaFollette, H. (2000) The Blackwell Guide to Ethical Theory, London: Blackwell.

Levitt, M. \& Williams, G. (2005) 'Ethical issues overview', Encyclopedia of Social Measurement Vol. 1, London, Elsevier.

Manson, N.C. \& O’Neill, O. (2007) Rethinking Informed Consent in Bioethics, Cambridge, Cambridge University Press.

Mason, J. (2007) 'Re-using' qualitative data: On the merits of an investigative epistemology', Sociological Research Online, 12, (3). Available online: http://www.socresonline.org.uk/12/3/3.html.

Mason, J. (2002) Qualitative Researching, London, Sage.

Mauthner, N. (2002) Ethics of Qualitative Research, London, Sage.

Mauthner, N. and Doucet, A. (2003) 'Reflexive accounts and accounts of reflexivity in qualitative data analysis', Sociology, 37(3), 413-431.

Mauthner, N., Parry, O. \& Backett-Milburn, K. (1998) 'The data are out there, or are they? Implications for archiving and revisiting qualitative data', Sociology, 32, (4) 733-745.

Miller, T. \& Boulton, M. (2007) 'Changing constructions of informed consent: Qualitative research and complex social worlds', Social Science and Medicine, (65), 2199-2211.

Moore, N. (2007) ‘(Re)Using qualitative data?’ Sociological Research Online, 12(3). Available online: http://www.socresonline.org.uk/12/3/1.html. 
NHMRC (2007) 'National Statement on Ethical Conduct in Human Research' (the National Statement), Commonwealth of Australia (Canberra), National Health and Medical Research Council, http://www.nhmrc.gov.au/ publications/synopses/e72syn.htm, Date Accessed: 16 January 2010.

OECD (2007) 'OECD Principles and Guidelines for Access to Research Data from Public Funding', Organization for Economic Cooperation and Development, Paris, http://www.oecd.org/dataoecd/9/61/38500813.pdf, Date Accessed: 16 January 2010.

O’Neill, O. (2002) A Question of Trust, Cambridge, Cambridge University Press.

O’Neill, O. (2003) 'Some limits of informed consent', Journal of Medical Ethics, (29), 4-7.

Parry, O. and Mauthner, N. (2005) 'Back to basics: Who re-uses qualitative data and why?', Sociology, 39(2), 337-342.

Parry, O. and Mauthner, N. (2004) 'Whose data are they anyway? Practical, legal and ethical issues in archiving qualitative research data,' Sociology, 38(1), 139-152.

RESPECT (2009) 'The RESPECT Code of Practice', Professional and Ethical Codes for Socio-Economic Research in the Information Society, http:// www.respectproject.org/code/index.php, Data Accessed: 16 January 2010.

RIN (2008) 'Stewardship of Digital Research Data', Research Information Network, http://www.rin.ac.uk/data-principles, Data Accessed: 16 January 2010.

Reynolds, P. (1979) Ethical Dilemmas and Social Science Research, San Francisco, Jossey-Bass.

Ruusalepp, R. (2008) 'A Comparative Study of International Approaches to Enabling the Sharing of Research Data', DCC and JISC, v1.6, 30 November, http://www.dcc.ac.uk/docs/publications/reports/Data_Sharing_ Report.pdf, Date Accessed: 16 January 2010.

Samuel, R. (1998) 'Perils of the transcript'. In R. Perks and A. Thomson (eds.), The Oral History Reader, London, Routledge.

Savage, M. (2005) 'Working-class identities in the 1960s: revisiting the Affluent Worker Study', Sociology, 39(5), 929-946.

Stanford Encyclopaedia of Philosophy (2009) 'Deontological Ethics', University of Stanford, http://plato.stanford.edu/entries/ethics-deontological/, Date Accessed: 16 January 2010.

Swan, A. and Brown, S. (2008) 'To Share or not to Share: Publication and Quality Assurance of Research Data Outputs', Research Information Network, http://www.rin.ac.uk/our-work/data-management-and-curation/sh are-or-not-share-research-data-outputs, Date Accessed: 16 January 2010.

Thane, P. and Evans, T. (forthcoming) Sinners? Scroungers? Saints? Unmarried Motherhood in Modern England. 
Thomas, R. and Walport, M. (2008) 'Data Sharing Review', Ministry of Justice, www.justice.gov.uk/reviews/datasharing-intro.htm, Date Accessed: 16 January 2010.

Thomson, D., Bzdel, L., Golden-Biddle, K., Reay, T., and Estabrooks, C. A. (2005) 'Central questions of anonymisation', Forum Qualitative Sozialforschung/Forum: Qualitative Social Research, 6(1), http://www. qualitative-research.net/index.php/fqs/article/view/511.

Timescapes (2009) 'The Data Archive', Timescapes, http://www.timescapes.leeds. ac.uk/the-archive/, Date Accessed: 16 January 2010.

UKDA (2008) 'Consent Forms', UK Data Archive, http://www.data-archive. ac.uk/sharing/consentforms.asp, Date Accessed: 16 January 2010.

UKDA (2009a) 'Defining Personal Data', UK Data Archive, http://www. data-archive.ac.uk/sharing/define.asp, Date Accessed: 16 January 2010.

UKDA (2009b) 'Manage and Share Data', UK Data Archive, http://www. data-archive.ac.uk/sharing/, Date Accessed: 16 January 2010.

Van den Eynden, V. (2008) 'Sharing research data and confidentiality: Restrictions caused by deficient consent forms', Research Ethics Review, 4(1), 37-38.

Van den Eynden, V. and Corti, L. (2009) 'Tensions between data sharing and data protection in research with people', SRA News, May, 12-15.

Wiles, R., Charles, V., Crow, G. and Heath, S. (2006) 'Researching researchers: Lessons for research ethics', Qualitative Research 6(3): 283-299.

Wiles, R., Heath, S., Crow, G., and Charles, V. (2005) 'Informed consent in social research: A literature review', NCRM Methods Review Paper, 001, http://eprints.ncrm.ac.uk/85/1/MethodsReviewPaperNCRM-001.pdf.

Wiles, R., Prosser, J., Bagnoli, A., Clark, A., Davies, K., Holland, S., and Renold, E. (2008) 'Visual ethics: Ethical issues in visual research', NCRM Review Paper, October (NCRM/011), http://eprints.ncrm.ac.uk/421/1/ MethodsReviewPaperNCRM-011.pdf.

Williams, M., Dicks, B., Coffey, A. \& Mason, B. (2007) 'Qualitative data archiving and reuse: mapping the ethical terrain', Methodological issues in qualitative data sharing and archiving, Briefing Paper 2, Cardiff, University of Cardiff, http://www.cardiff.ac.uk/socsi/hyper/QUADS/Briefing\%20 paper $\% 20$ ethics.pdf. 